\title{
Processos e práticas de formalizaçáo da Terapia Ocupacional na Assistência Social: alguns marcos e desafios ${ }^{1}$
}

\author{
Marta Carvalho de Almeida ${ }^{a}$, Carla Regina Silva Soares ${ }^{b}$, \\ Denise Dias Barros', Débora Galvani ${ }^{d}$
}

\begin{abstract}
aDoutora em Saúde Coletiva, Universidade Estadual de Campinas - UNICAMP, Professora Doutora, Departamento de Fisioterapia, Fonoaudiologia e Terapia Ocupacional, Universidade de São Paulo - USP, São Paulo, SP, Brasil

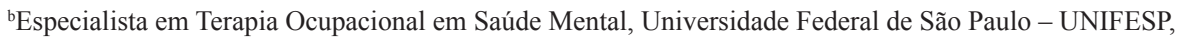
Terapeuta Ocupacional do Departamento de Fisioterapia, Fonoaudiologia e Terapia Ocupacional, Universidade de São Paulo - USP, São Paulo, SP, Brasil

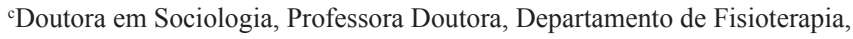

Fonoaudiologia e Terapia Ocupacional, Universidade de São Paulo - USP, São Paulo, SP, Brasil

${ }^{\mathrm{d}}$ Doutoranda em Psicologia Social, Terapeuta Ocupacional, Departamento de Fisioterapia,

Fonoaudiologia e Terapia Ocupacional, Universidade de São Paulo - USP, São Paulo, SP, Brasil
\end{abstract}

\begin{abstract}
Resumo: $\mathrm{O}$ artigo tem por objetivo discutir a prática profissional dos terapeutas ocupacionais no Sistema Único de Assistência Social-SUAS, adotando a perspectiva de que esta é pertinente e atravessada por desafios. Com base na análise da experiência que vem se desenvolvendo como projeto de extensão universitária do curso de terapia ocupacional da Universidade de São Paulo, destacam-se conceitos, diretrizes organizativas e operacionais da Política Nacional de Assistência Social e do SUAS, em suas conexões com a Terapia Ocupacional, seus compromissos éticos, fundamentos e metodologias. Compreende-se o compromisso com a inclusão e a efetiva participação social de pessoas e coletivos em situação de vulnerabilidade como fundamentos éticos da terapia ocupacional, que sustentam a sua integração às novas perspectivas da Assistência Social brasileira. São identificados alguns desafios importantes, tais como a necessidade de aprofundar o conhecimento acerca dos processos sociais envolvidos na violação de direitos dos grupos vulneráveis e, por consequência, qualificar a intervenção profissional sobre eles. Conclui-se que os terapeutas ocupacionais podem contribuir com a implantação do SUAS, com seus serviços e com a assistência por eles desenvolvida, destacando-se a necessidade de que se oponham aos elementos normativos e disciplinadores contidos nas práticas profissionais, que servem ao enquadramento, dominação e controle dos grupos considerados em condição de vulnerabilidade.
\end{abstract}

Palavras-chave: Assistência Social, Terapia Ocupacional, Vulnerabilidade Social.

\section{Formalization processes and practices of Occupational Therapy in Social Assistance: landmarks and challenges}

\begin{abstract}
The purpose of this article was to discuss the professional practice of occupational therapists in the "Sistema Único de Assistência Social - SUAS" (Social Assistance Central System), under the perspective that it is pertinent and faces challenges. Based on the analysis of the experience developed as a university extension project of the Occupational Therapy course at the Universidade de São Paulo (University of Sao Paulo), emphasis is placed on the concepts and the organizational and operational guidelines of the National Policy of Social Assistance in their connections with Occupational Therapy, its ethical commitments, foundations and
\end{abstract}

Autor para correspondência: Marta Carvalho de Almeida, Universidade de São Paulo - USP, Rua Cipotânea, 51, Cidade Universitária Armando de Salles Oliveira, Butantã, CEP 05360-000, São Paulo, SP, Brasil, e-mail: mcarmei@usp.br

Recebido: 3/2/2012; Aceite final: 23/3/2012. 
methodologies. Ethical foundations of the profession, such as commitment to social inclusion and effective participation of people and groups that are in vulnerable positions are pointed out as aspects that support the integration of occupational therapy with the new perspectives of the Brazilian Social Assistance field. Some important challenges have also been identified, such as the need to develope our knowledge about the social processes involved in the violation of rights of vulnerable groups and, consequently, qualify the professional assistance to these groups. Finally, occupational therapists are able to collaborate with "SUAS" and its assistance services, observing the need to object to the disciplinary actions that constrain, dominate and control groups that are in vulnerable positions.

Keywords: Social Assistance, Occupational Therapy, Social Vulnerability.

\section{Introdução}

Em junho de 2011 a Resolução no 17 do Conselho Nacional de Assistência Social - CNAS (BRASIL, 2011) - reconheceu as categorias profissionais de nível superior que devem atender às especificidades dos serviços socioassistenciais, bem como das funçóes essenciais de gestáo do Sistema Único de Assistência Social - SUAS. Dentre estas, a terapia ocupacional figura como profissão que pode integrar as equipes de referência, respeitando-se a necessidade de estruturação e composição dos serviços a partir das particularidades locais e regionais, do território e das necessidades dos usuários. Além disso, está entre as profissóes preferenciais para compor a gestão do SUAS.

Os terapeutas ocupacionais, com toda a razão, comemoraram. Por um lado, porque se considerou que essa Resoluçáo trouxe o reconhecimento de uma prática que se efetiva e que se vem aprimorando de modo consistente desde a década de 1970 (SOARES, 1991). Por outro, a comemoração também se deveu ao fato de que o conteúdo da Resolução CNAS $\mathrm{n}^{\circ} 17$ de 2011 refletiu a participação organizada da categoria profissional no processo de discussão que, apoiado pelo CNAS, reuniu os trabalhadores da Assistência Social e os gestores de diferentes níveis buscando definir quem são os trabalhadores do SUAS. Esse processo foi instalado como forma de atender à Resoluçâo CNAS no 172, de 2007 (BRASIL, 2007), que recomendou a instituição de Mesas de Negociaçôes com composição paritária entre gestores, prestadores de serviço e trabalhadores da área de assistência do setor público e do setor privado, como forma de conduzir a gestão do trabalho no âmbito do SUAS2. Para que se convocasse as categorias profissionais que representam os trabalhadores do SUAS, fazia-se necessário definir claramente quais seriam estas. Desse modo, terapeutas ocupacionais de todo o Brasil, especialmente os que atuam no âmbito da Assistência Social e da Terapia Ocupacional Social, encontraram oportunidades de discutir a complexidade do trabalho no SUAS e o lugar da profissão no contexto atual, fazendo-se presentes nos Fóruns e Encontros Regionais e Estaduais de Trabalhadores. Estes precederam o Encontro Nacional de Trabalhadores do SUAS, ocorrido em Março de 2011 em Brasília, contando com cerca de 350 participantes, sendo destes aproximadamente 40 terapeutas ocupacionais.

Em todas essas ocasióes, os intercâmbios entre colegas terapeutas ocupacionais que atuam na área, $e$ destes com as demais profissōes, constituíram ocasióes fundamentais para o aprofundamento de temas relevantes para a melhoria da qualidade dos serviços oferecidos à população e também para produzir uma melhor projeção acerca das possibilidades e responsabilidades da terapia ocupacional no SUAS, com base nos compromissos éticos e políticos da profissão, e também nos desafios atuais da implantação da Política Nacional de Assistência Social (PNAS) (BRASIL, 2004).

Em verdade, vale ressaltar que a organização dos terapeutas ocupacionais, tomando o SUAS como eixo central, já havia se iniciado um pouco antes. Ela teve forte impulso a partir de agosto de 2010, por ocasião da abertura da Consulta Pública sobre a Norma Operacional Básica - NOB -SUAS 2005 (BRASIL, 2005) - por meio da qual se propôs a revisão de sua redação, projetando-se uma "NOB-SUAS 2010". A categoria se organizou para analisar o documento-base proposto pelo CNAS e participar criticamente da revisão da $\mathrm{NOB}$, de modo a enviar sugestôes que contribuíssem com o avanço da constituição e consolidação do SUAS no Brasil, ou seja, de forma consoante à motivação do processo de revisão.

A ABRATO - Associação Brasileira de Terapeutas Ocupacionais - teve papel fundamental nesse percurso. Além de deflagrar e dar apoio à organização dos profissionais, esteve sempre presente nos momentos e espaços políticos em que a associação 
de classe era um interlocutor importante. O Conselho Federal de Fisioterapia e Terapia Ocupacional (2010), por sua vez, a partir da reivindicação da categoria, editou em 2010 a Resolução no 383, na qual se definiram as competências profissionais da Terapia Ocupacional no âmbito social. A elaboração dessa Resoluçấo contou com assessoria de profissionais de diferentes regiōes do Brasil engajados no processo de discussão sobre a implantação do SUAS, tendo sido esse um dos prováveis motivos pelo qual a Resoluçáo se articula coerentemente aos esforços para qualificar as práticas desenvolvidas no campo social.

Como contribuição, também o Projeto METUIA3, em conjunto com a ABRATO, organizou e elaborou documento que, tomando por referência a Tipificação Nacional de Serviços Socioassistenciais (BRASIL, 2009a), buscou elucidar as principais ações do terapeuta ocupacional no contexto dos serviços e programas da Assistência Social.

Diante deste cenário, que parece deixar claro que a terapia ocupacional alcançou novos patamares de formalização no campo social, importantes desafios vêm sendo colocados. Envolvem desde a necessidade de aprimorar a compreensão e, consequentemente, as intervençôes profissionais sobre os problemas específicos do campo social (incluindo a gestáo dos serviços), até a necessidade de formar profissionais qualificados para operar criticamente com conceitos, instrumentos, recursos e desafios da Política Nacional de Assistência Social. Essa tarefa precisa ser enfrentada pela Terapia Ocupacional de modo a produzir efeitos em dois níveis: tanto no fortalecimento de sua articulação com o conjunto de trabalhadores da Assistência Social e seu contexto de tarefas, desenvolvimento e lutas, quanto na sua capacidade de responder, de sua perspectiva específica, às necessidades sociais da população atendida.

Tomando essa diretriz como referência, desde fevereiro de 2011, o Projeto METUIA -USP vem realizando atividades 4 em um Centro de Referência de Assistência Social na cidade de São Paulo, e também trabalhando junto à equipe que realiza as açóes de proteção especial no mesmo território de abrangência. Ao longo de 2011, docentes, terapeutas ocupacionais e estudantes da universidade atuaram em atividades promovidas para famílias participantes do Programa de Erradicação do Trabalho Infantil (PETI), para famílias que apresentam situaçóes de violaçáo de direitos (especialmente situaçóes de negligência com crianças e idosos e violência doméstica) e também nas atividades dirigidas aos jovens participantes do programa ProJovem. Reforçando a metodologia de trabalho que vem se desenvolvendo há alguns anos no METUIA, das intervenções realizadas em grupo desdobraram-se ações particularizadas, por meio das quais houve acompanhamento de demandas específicas e de projetos de vida.

Essa experiência, que vem se consolidando e ampliando com o tempo, tem sido o pano de fundo de nossas reflexóes sobre a terapia ocupacional e o SUAS. Essas reflexôes, porém, estão particularmente referidas às questôes que envolvem as práticas que devem ocorrer em unidades públicas estatais - CRAS e CREAS - que são apenas uma parte do SUAS. Certamente, as características específicas de nossa prática e de seu contexto definem o contorno de nossas preocupaçóes. A Terapia Ocupacional Social (BARROS; LOPES; GALHEIGO, 2007), por sua vez, fundamenta nossa perspectiva crítica.

\section{Pontos de referência:}

a Política Nacional de
Assistência Social e as
definições, princípios e
diretrizes que norteiam a
prática

Um aspecto fundamental de nossas reflexões diz respeito aos elementos que constituem a Política Nacional de Assistência Social e suas implicaçóes no trabalho do terapeuta ocupacional. Obviamente, toda ação profissional se dá em um determinado campo político, marcado por embates e disputas entre diferentes projetos que visam orientar as açóes realizadas nesse âmbito. É essencial que os terapeutas ocupacionais posicionem-se criticamente em face desses projetos, conhecendo-os, compreendendo suas raízes históricas e sendo capazes de analisar suas influências na realidade concreta do dia a dia dos serviços. É preciso, em outras palavras, reconhecer e inserir sua ação profissional num claro projeto societário, cuja dimensão política, com suas contradiçôes, deve ser passível de análise.

$\mathrm{Na}$ Assistência Social brasileira, vários marcos pontuam o desenho atual do campo. Um dos mais importantes é a Constituição de 1988 (BRASIL, 1988) que, contextualizada no curso do movimento democrático e popular da sociedade brasileira, expressou o anseio de que se promovessem alteraçóes substanciais na esfera da seguridade social. O caráter não contributivo da proteção social, bem como o delineamento da Assistência Social como direito, foram por ela instituídos. Mas somente em 1993 a Lei Orgânica da Assistência Social (BRASIL, 1993) estabeleceu bases mais claras para que se revertesse 
a abordagem vigente, na qual serviços e auxílios assistenciais eram fornecidos como favores, de forma descontínua, sem qualidade e sem financiamento próprio, condicionados aos interesses políticos dos governantes (PEREIRA, 1996).

Passados 10 anos de trajetória da LOAS, a IV Conferência Nacional de Assistência Social teve que insistir na constituição de metas e prazos para a implantação do Sistema Único de Assistência Social - SUAS, enquanto sistema federativo, público, não contributivo, descentralizado e participativo, conforme determinava a LOAS. Para se chegar à sua instituição legal, em 2005, os princípios constituintes da LOAS balizaram a revisão e a aprovação da Política Nacional de Assistência Social em 2004, na qual se definiu um modelo de implantação, gestão, financiamento e controle social da política pública de Assistência Social, bem como as diretrizes de execução de programas, projetos, serviços socioassistenciais e benefícios, organizados numa escala hierárquica e complementar (TAPAJÓS; CRUS; ALBUQUERQUE, 2007). Segundo a PNAS, seus objetivos visam a integração da política assistencial às demais, setoriais, a garantia dos mínimos sociais e a universalizaçáo de direitos para a população em situação de vulnerabilidade e risco, conforme os parâmetros determinados por meio de análise das condiçôes de vida desiguais, relacionadas ao padrão econômico/nível de concentração de renda. Assim, sáo definidos como usuários da PNAS os indivíduos e as famílias com histórico de perda ou fragilidade de vínculos de afetividade, pertencimento e sociabilidade (em determinadas circunstâncias, associada a ciclos de vida); com desvantagem no acesso às demais políticas públicas; pessoas com deficiência; pessoas excluídas pela pobreza e inserção precária ou não inserção no mercado formal e informal de trabalho; com envolvimento em diferentes formas de violência advinda do núcleo familiar e grupos; e indivíduos em estratégias de sobrevivência capazes de gerar risco pessoal e social (BRASIL, 2004).

Para o acompanhamento dos complexos processos que envolvem essas condiçóes, a PNAS define a matricialidade sócio-familiar como eixo estruturante das açóes desenvolvidas, ou seja, que a família seja o foco da proteção social. Considerada em seus diversos formatos e arranjos, a família é compreendida como um conjunto de pessoas interligadas por laços consanguíneos, afetivos e/ou de solidariedade, que atua como núcleo social primário de convívio e afetividade, mediador das relaçóes entre o público e o privado, capaz de oferecer proteção e guarda aos seus membros. A centralidade na família pretende superar a lógica individualista e contribuir com o fortalecimento e a sustentabilidade deste núcleo para o enfrentamento das adversidades e para a emancipação coletiva (BRASIL, 2004). Contudo, tem se salientado a importância de não se responsabilizar as famílias pelos seus problemas, dificuldades e condiçóes de vulnerabilidade, e a necessidade de se romper com a noção de que cabe às famílias ou às pessoas a responsabilidade de superar as dificuldades criadas pelos efeitos perversos das políticas econômicas e pela falta de proteçáo social.

Os serviços de atenção às famílias, bem como as outras modalidades de acompanhamento, são previstos como parte da proteção social organizada em níveis de proteção básica e especial (de média e alta complexidades), a partir da oferta de serviços, programas, projetos e benefícios socioassistenciais implantados em territórios de maior vulnerabilidade social. Segundo Tapajós, Crus e Albuquerque (2007), desde 2004 o SUAS tem conseguido avanços na atuação e efetivação das açóes, principalmente a partir do progresso na implantaçáo dos CRAS e CREAS, caracterizados como as portas de entrada para o SUAS e orientados pelas diretrizes da Norma Operacional Básica -NOB-SUAS/2005.

A proteção social básica visa promover ações de prevenção a situações de vulnerabilidade e é representada essencialmente pelo CRAS. Tal equipamento é responsável por organizar a rede socioassistencial local e atuar diretamente nas questóes prevalentes no seu território de abrangência. Para as situaçóes instaladas e agravadas de risco social e violação de direitos, o CREAS deve promover intervençóes imediatas de proteção e acompanhamento técnico especializado por equipe multiprofissional (proteçáo social especial), em constante articulação com o conjunto da rede socioassistencial (BRASIL, 2009b).

Além da inserção e acompanhamento da população em projetos, programas e serviços socioassistenciais, a PNAS prevê uma política de transferência de renda. Essa proposição, que contempla a segurança monetária como garantia de sobrevivência de pessoas e grupos familiares, está alicerçada na inclusão da Assistência Social como parte da Seguridade Social brasileira (BRASIL, 2004). Neste sentido, a organização do SUAS visa associar o acesso dos usuários ao equipamento de referência à concessão de benefícios (renda) que pretendem assegurar a estes os mínimos sociais (BRASIL, 2009b).

O debate em torno dos Programas de Transferência de Renda (PTRs), no entanto, é extenso, comportando diferentes posiçóes. Para Silva (2004), entre outros autores, os PTRs pretendem romper com o ciclo de 
reprodução de pobreza no Brasil. A autora aponta a pobreza como elemento impulsionador da construção da política pública de assistência social, por estar localizada como eixo central de uma conjuntura de resultantes como violência, trabalho infantil, baixa escolaridade, defasagem em relação ao mercado de trabalho, entre outros, que geram a necessidade de proteção social do Estado. Contudo, de acordo com o Plano de Assistência Social da Cidade de São Paulo 2009-2012 (SÃO PAULO, 2010, p. 24), os quesitos "renda" e/ou "pobreza", se considerados isoladamente, são insuficientes para caracterizar o público alvo das açóes da Assistência Social, pois são incapazes de discriminar "o estado real de privação da família". Para tanto, segundo o documento, faz-se necessário avaliar e diferenciar os níveis de pobreza a fim de legitimar a equidade como princípio norteador das políticas públicas. Desta forma, a condição de pobreza deve estar associada a distintas situaçóes de privação social, tais como: desamparo pela ação do poder público, famílias com crianças pequenas que necessitam de maior assistência pública, inserção precária no mercado de trabalho, entre outros.

Já Araújo et al. (2009) discutem que, historicamente, as políticas sociais brasileiras não atuaram na correção de desigualdades de padrôes econômicos e tampouco geraram oportunidades de reduzir a disparidade de condiçóes de vida. Assim, os arranjos políticos contemporâneos tendem a atuar embasados pela lógica mercantil, de modo focal e emergencial, direcionados a situaçóes extremas de pobreza (SOARES, 2000 apud ARAÚJO et al., 2009). Para os autores, a condiçáo de pobreza definida pela política social legitima o lugar da náo cidadania e reduz o fenômeno social em carência e incapacidade, transformando o direito em "mérito de necessidade", mediante a exigência de comprovação de situações precárias de vida.

De fato, o padrão de renda associado à carência de satisfação das necessidades básicas dos indivíduos e suas famílias são determinantes para a delimitação da população alvo do SUAS, levando-se em conta a definição da PNAS sobre situaçôes de vulnerabilidade e risco (ARAÚJO et al., 2009). No entanto, Cunha (2004) ressalta a ampla discussão sobre o conceito de vulnerabilidade apontando a existência de 18 definiçóes diferentes que apresentam como ideia comum a referência à "capacidade de resposta diante de risco ou constrangimentos”. Para o autor, uma das definiçôes mais relevantes é a de Kaztman (KAZTMAN, 1999 apud FERREIRA; DINI; FERREIRA, 2006), que compreende a vulnerabilidade como a maior ou menor capacidade e/ou recurso de um indivíduo, família ou grupo social em lidar com fatores que afetam o bem-estar e criar/encontrar respostas positivas às oportunidades oferecidas pelo ambiente, considerando as condiçóes de saúde, educação, trabalho e acesso a bens materiais e políticos.

No Estado de Sáo Paulo, o conceito defendido por Kaztman, associado aos dados demográficos, escolares e de renda; gerou o Índice Paulista de Vulnerabilidade Social - IPVS (FERREIRA; DINI; FERREIRA, 2006). Organizado pela Fundação SEADE em 2004, revelou que, de acordo com a localização espacial, 8,5\% dos setores censitários, ou seja, 2,5 milhóes de pessoas pertenciam a áreas de "nenhuma vulnerabilidade" (p. 11), enquanto $8,6 \%$, o equivalente a 3,6 milhões de pessoas, foram identificadas em áreas de "vulnerabilidade muito alta" (p. 11).

Em escala nacional, o Mapa de Pobreza e Desigualdade, realizado pelo Instituto Brasileiro de Geografia e Estatística (2003), apontou nesta mesma data, que $32,6 \%$ dos municípios brasileiros tinham mais da metade de sua população vivendo na pobreza. Os resultados do Censo 2010 (INSTITUTO..., 2011) mostraram que, apesar da diminuição ocorrida nos últimos anos, o índice de desigualdade brasileiro ainda é bastante alto. A pesquisa apontou que, em 2010 , embora a média nacional de rendimento domiciliar per capita de R \$ 668,00 ultrapassasse o valor do salário mínimo vigente ( $\mathrm{R} \$ 510,00), 25 \%$ da população recebia até $\mathrm{R} \$ 188,00$ e metade dos brasileiros até R \$ 375,00 (INSTITUTO..., 2011).

Esses dados mostram que, inequivocamente, a extensão da pobreza na nossa população é significativa. Tomando esse fato, Gomes e Pereira (2005) afirmam que a situação socioeconômica é o fator que mais contribui para a desestruturação familiar, pois, ao se deparar com as dificuldades em cumprir satisfatoriamente a sua funçâo básica de socialização e amparo, a família inicia um processo desencadeador de situaçôes de vulnerabilidade, que repercute diretamente nos mais jovens e frágeis. Percebe-se, então, o rompimento de vínculos e a sucessão de situaçóes de sofrimento que afrouxam os laços de solidariedade e afeto do âmbito familiar. Desse modo, diante da privaçáo e da necessidade de criar estratégias de sobrevivência, os membros da família, e principalmente os mais jovens, submetem-se a precárias condiçóes de trabalho, moradia e convivência, acarretando recorrentes episódios de violação de direitos e violência. De acordo com Cardia (2012), a superposição de carências, ou seja, a baixa escolaridade, condições de saúde precárias, famílias chefiadas por mulheres5, privação econômica, entre outros, associada à grande populaçáo jovem, 
produz maior risco de envolvimento em situaçóes de violência e em um ciclo reprodutivo de condiçóes precárias de sobrevivência.

Concluindo, a Política de Assistência Social nos coloca num campo em que a vulnerabilidade de pessoas, grupos e coletivos é multifacetada e abrangente. Se a interrupção dos ciclos de violação de direitos pode se dar apenas com a estruturação de políticas públicas, ainda que de natureza intersetorial, de caráter continuado e sistemático, com a oferta de serviços universais e a inversão da lógica de responsabilização individual para a superação de processos danosos e estigmatizantes, esta, certamente, é a base de muitas questóes. Afinal, a vulnerabilidade e o risco social são produtos das características estruturais da sociedade brasileira e, como tais, nos obrigam a operar com a contradição que isso representa.

\section{Ações da Terapia Ocupacional no SUAS: dos compromissos e competências profissionais $\mathrm{e}$ suas potencialidades}

Por meio da exposição e reflexão acerca de alguns pontos relevantes de nossa experiência de trabalho no SUAS, buscamos discriminar o que nos tem parecido ser algumas potencialidades da terapia ocupacional nessa esfera. Nossa intenção é de que estas consideraçóes cumpram o papel de estimular novas discussóes, ativem nossa capacidade de produzir boas questôes e, em última instância, nos auxiliem a qualificar nossa atuação na Assistência Social.

O primeiro aspecto que nos parece conveniente apontar é que a inclusão da terapia ocupacional no elenco de ofertas assistenciais dos serviços tem se mostrado pertinente. Nossos objetivos gerais de trabalho, bem como nossas estratégias e tecnologias, têm se articulado de modo coerente às diretrizes do SUAS, bem como às peculiaridades do CRAS e do CREAS, que buscam atender às especificidades do território em que se situam e de suas demandas sociais. Assim, vale mencionar que nossos principais objetivos junto à população anteriormente mencionada, têm sido:

- prevenir a ruptura de vínculos familiares e comunitários;

- aumentar a capacidade protetiva das famílias;

- fortalecer as relaçóes de interdependência, os vínculos familiares, as trocas sociais e os vínculos entre família e comunidade;
- favorecer o acesso às oportunidades de desenvolvimento pessoal dos sujeitos participantes e também do enriquecimento do repertório ocupacional e vivencial das famílias;

- ampliar o acesso das famílias às redes sociais de apoio à criança, ao adolescente, ao adulto, ao idoso e à família;

- promover o reconhecimento, o respeito e o exercício de direitos e deveres individuais e coletivos;

- favorecer o acesso daqueles que tiveram direitos violados a vivências que promovam a autovalorização e o sentimento de pertencimento comunitário;

- apoiar a elaboração e o desenvolvimento de projetos de vida que envolvam formas alternativas de sobrevivência, de convivência e de participação social, fundamentadas tanto na análise das possibilidades reais da família e suas redes, quanto nas exigências de engajamento em processos sociais mais amplos.

No sentido de alcançar esses objetivos, o uso da atividade como tecnologia de mediação sócioocupacional tem se mostrado um importante caminho (CONSELHO..., 2010).

O trabalho em equipe segue de modo colaborativo, sendo aspecto bastante conhecido dos terapeutas ocupacionais. Temos compartilhado de forma responsável e ativa junto às equipes as dificuldades $\mathrm{e}$ buscas para superar concepçóes assistencialistas que, com diferentes faces, se apresentam no trabalho. A relação profissional-usuário, por exemplo, comporta uma dimensão conflituosa, na medida em que as expectativas iniciais dos usuários ainda correspondem a um modelo de relaçáo verticalizada, na qual o profissional assume um lugar imperativo no curso da intervençáo e, na maior parte das vezes, centra a finalidade do trabalho na inclusão do usuário no PTR. Na ausência desse padrão de relacionamento, é somente depois de certo período de contato que as interaçóes passam a fluir baseadas em novas expectativas e se podem vislumbrar as possibilidades de adesão dos usuários a relaçóes mais abertas à sua participação e mais condicionadas às suas próprias decisôes. Aliás, nesse aspecto em particular, a formaçáo do terapeuta ocupacional - que enfatiza a alteridade, a diversidade, a cultura e a pluralidade como chaves de leitura da realidade social - tem nos parecido bastante apropriada aos desafios da atuação na Assistência Social. Nossas competências profissionais ligadas à escuta, ao acolhimento e à geração e manutenção de relaçóes ancoradas 
na autonomia do Outro têm sido fundamentais. Especialmente em se tratando de populaçôes vulneráveis, isso ganha destaque, uma vez que nosso compromisso ético-político remete à inclusão social desses segmentos associada a sua efetiva participação na produção de bens e valores sociais de modo geral, e em seus contextos próprios, em seus cotidianos, de modo particular. Trabalhando com a complexidade de fatores que promovem o empoderamento pessoal e/ou coletivo (AMERICAN..., 2008), terapeutas ocupacionais estấo aptos a atuarem profundamente conectados a projetos emancipatórios, nos quais o respeito e o apoio à autonomia dos sujeitos representa condição essencial. Tal noção de autonomia deve remeter ao desenvolvimento da capacidade de reflexão e de engajamento coletivos (TEIXEIRA, 2010).

Do mesmo modo, a habilidade do terapeuta ocupacional para operar com atividades em grupo tem se mostrado um fator muito positivo para o trabalho. A possibilidade de propor e orientar atividades grupais tem se somado a outros esforços para qualificar a assistência aos usuários, em consonância com o que se vem preconizando na legislação, que as toma enquanto importante ferramenta para se alcançar os impactos sociais esperados (BRASIL, 2009a). Assim como aponta Teixeira (2010), a promoção deste espaço não assume caráter terapêutico, mas sim a oportunidade de refletir e trocar experiências, e garantir escuta e acolhida qualificada para a compreensão da história familiar, dos modos de vida e da relaçáo com o exercício do direito e da cidadania.

Enfim, nossa experiência tem mostrado que os terapeutas ocupacionais reúnem habilidades significativas para manejar um conjunto diversificado de estratégias de intervenção face às demandas identificadas nos serviços, incluindo-se, especialmente, o trabalho no território, na realidade local. Contudo, certamente há muito adensamento técnico, ético e político a se produzir no campo da Assistência Social. Dentre os desafios que se colocam, é urgente que possamos aprofundar reflexóes sobre as competências profissionais exigidas para o trabalho no campo sob a perspectiva da universalização dos direitos e projetá-las coerentemente na formação profissional. Isso deve acontecer tomando por referência tanto as demandas sociais da população quanto as demandas de consolidação do SUAS, no qual a gestão cumpre um importante papel. Na terapia ocupacional, ainda temos também muito que avançar no sentido de conhecer as várias dimensôes do problema da violação de direitos praticada em relação a diferentes segmentos populacionais. Consequentemente, desenvolver estratégias compatíveis com a complexidade desse problema na sociedade brasileira é uma tarefa que deve nos mobilizar. Atravessando essas tarefas, devemos primar pelo desvelamento dos paradoxos compreendidos nas açóes sociais na sociedade contemporânea, atentando para conceitos, enunciados explícitos e implícitos, proposiçóes, metodologias e técnicas que servem ao enquadramento, dominaçâo e controle dos grupos considerados em condição de vulnerabilidade. Esses operam quase sempre associados à atribuição de incompetência à população assistida. Problematizar nossa prática profissional também é potencializá-la.

\section{Referências}

AMERICAN OCCUPATIONAL THERAPY ASSOCIATION - AOTA. Occupational Therapy Practice Framework: Domain \& Process. American Journal of Occupational Therapy, v. 62, n. 6, p. 625-683, 2008. PMid:19024744. http://dx.doi.org/10.5014/ajot.62.6.625

ARAÚJO, C. C. et al. Relação entre pobreza e trabalho no Brasil: expressão de seus dilemas na Política de Assistência Social. In: JORNADA INTERNACIONAL DE POLÍTICAS PÚBLICAS: Neoliberalismo e Lutas Sociais: perspectivas para as políticas públicas, 4., 2009, São Luís. Anais... São Luís: UFMA, 2009.

BARROS, D. D.; LOPES, R. E.; GALHEIGO, S. M. Terapia Ocupacional Social: concepçóes e perspectivas. In: CAVALCANTI, A.; GALVÃO, C. Terapia Ocupacional: fundamentação e prática. Rio de Janeiro: Guanabara Koogan, 2007. p. 347-353.

BRASIL. Constituição (1988). Constituição da República Federativa do Brasil de 1988. Diário Oficial da República Federativa do Brasil, Poder Executivo, Brasília, DF, 5 out. 1988. Seção 1. Disponível em: <www.senado.gov. br/legislacao/const/>. Acesso em 9 jan 2012.

BRASIL. Presidência da República. Lei Orgânica da Assistência Social, no 8.742, de 7 de dezembro de 1993. Dispóe sobre a organização da Assistência Social e dá outras providências. Diário Oficial da República Federativa do Brasil, Poder Executivo, Brasília, DF, 8 dez. 1993. Seção 1. Disponível em: <http://www.planalto.gov.br/ ccivil_03/leis/L8742.htm>. Acesso em: 09 jan 2012.

BRASIL. Ministério do Desenvolvimento Social e Combate à Fome. Politica Nacional de Assistência Social. Brasília: Secretaria Nacional de Assistência Social, 2004.

BRASIL. Ministério do Desenvolvimento Social e Combate à Fome. Norma Operacional Básica NOB/SUAS. Brasília: Secretaria Nacional de Assistência Social, 2005.

BRASIL. Ministério do Desenvolvimento Social e Combate à Fome. Conselho Nacional de Assistência Social. Resolução no 172, 20 de setembro de 2007. Recomenda a instituição de Mesa de Negociação na forma estabelecida na Norma Operacional de Recursos Humanos do Sistema Único de Assistência Social/ NOB-RH/SUAS. Diário Oficial da República Federativa do Brasil, Poder Executivo, Brasília, DF, 4 out. 2007. Seção 1. Disponível em: <http://www.mds.gov.br/cnas/ legislacao/legislacao/resolucoes/legislacao/resolucoes/ 
arquivos-2007/resolucoes-normativas-exercicio-de-2007>. Acesso em: 04 jan. 2012.

BRASIL. Ministério do Desenvolvimento Social e Combate à Fome. Resolução no 109, de 11 de novembro de 2009. Tipificação Nacional de Serviços Socioassistenciais. Diário Oficial da República Federativa do Brasil, Poder Executivo, Brasília, DF, 25 nov. 2009a. Seção 1.

BRASIL. Ministério do Desenvolvimento Social e Combate à Fome. SUAS: Sistema Único de Assistência Social. Brasília: Secretaria Nacional de Assistência Social, 2009b.

BRASIL. Ministério do Desenvolvimento Social e Combate à Fome. Resoluçáo no 17, de 20 de junho de 2011. Ratificar a equipe de referência definida pela Norma Operacional Básica de Recursos Humanos do Sistema Único de Assistência Social - NOB-RH/SUAS e Reconhecer as categorias profissionais de nível superior para atender as especificidades dos serviços socioassistenciais e das funçóes essenciais de gestão do Sistema Único de Assistência Social - SUAS. Diário Oficial da República Federativa do Brasil, Poder Executivo, Brasília, DF, 21 jun. 2011. Seção 1. Disponível em: <http://www.sedest.df.gov.br/ sites/300/382/00002355.pdf>. Acesso em: 04 jan. 2012.

BRASIL. Ministério do Desenvolvimento Social e Combate à Fome. CapacitaSuas Volume. SUAS: Configurando os Eixos de Mudança. Brasília: Ministério de Desenvolvimento Social e Combate à Fome, 2008.

CARDIA, N. Jovens, violência fatal, superposiçâo de carências e mercado de trabalho. São Paulo: NEVI USP, 2005. Disponível em: <http://www.nevusp. org/ downloads/down074.pdf>. Acesso em: 06 jan. 2012.

CONSELHO FEDERAL DE FISIOTERAPIA E TERAPIA OCUPACIONAL - COFFITO. Resolução no 383, de 22 de dezembro de 2010. Define as competências do Terapeuta Ocupacional nos Contextos Sociais e dá outras providencias. Diário Oficial da República Federativa do Brasil, Brasília, DF, 25 dez. 2010. Disponível em: <http://www.coffito.org.br/publicacoes/pub_view. asp? cod=1960\&psecao=9>. Acesso em: $12 \mathrm{dez} .2011$.

CUNHA, J. M. P. Um sentido para a vulnerabilidade sociodemográfica nas metrópoles paulistas. Revista Brasileira de Estudos de População, v. 21, n. 2, p. 343-347, 2004.
GOMES, M. A.; PEREIRA, M. L. D. Família em situação de vulnerabilidade social: uma questão de políticas públicas. Ciência e Saúde Coletiva, v. 10, n. 2, p. 357-363, 2005. http://dx.doi.org/10.1590/S1413-81232005000200013 INSTITUTO BRASILEIRO DE GEOGRAFIA E ESTATÍSTICA - IBGE. Censo Demográfico 2000 e Pesquisa de Orçamentos Familiares - POF 2002/2003. Mapa de Pobreza e Desigualdade. Brasil: IBGE, 2003. Disponível em: <http://www.ibge.gov.br/home/presidencia/ noticias/noticia_visualiza.php?id_noticia=12938id_ pagina=1>. Acesso em: 16 jan. 2012.

INSTITUTO BRASILEIRO DE GEOGRAFIA E ESTATÍSTICA - IBGE. Censo Demográfico 2010. Brasil: IBGE, 2011. Disponível em: <http://www.censo2010. ibge.gov.br/resultados_do_censo2010.php>. Acesso em: 15 jan. 2012.

FERREIRA, M. P.; DINI, N. P.; FERREIRA, S. P. Espaços e dimensóes da pobreza nos municípios do Estado de São Paulo: Índice Paulista de Vulnerabilidade Social - IPVS. São Paulo em Perspectiva, v. 20, n. 1, p. 5-17, 2006.

PEREIRA, P. A Assistência social na perspectiva dos direitos: Crítica aos padrôes dominantes de proteção aos pobres no Brasil. Brasília: Ed. Thesaurus, 1996.

SÃO PAULO. Secretaria Municipal de Assistência e Desenvolvimento Social. Plano de Assistência Social - PLAS da Cidade de São Paulo 2009-2012. São Paulo: Secretaria Municipal de Assistência Social, 2010.

SILVA, M. O. S. Os Programas de Transferência de Renda na Política Social Brasileira: seu desenvolvimento, possibilidades e limites. Revista de Politicas Públicas, v. 8, n. 2, p. 113-133, 2004.

SOARES, L. B. T. Terapia ocupacional: lógica do capital ou do trabalho? São Paulo: Editora Hucitec, 1991.

TAPAJÓS, L.; CRUS, J. F.; ALBUQUERQUE, S. A. (Orgs.). Sistema Único de Assistência Social-SUAS. Brasília: Secretaria Nacional de Assistência Social, 2007.

TEIXEIRA, S. M. Trabalho Interdisciplinar nos CRAS: um novo enfoque e trato à pobreza? Textos \& Contextos, v. 9, n. 2, p. 286-297, 2010.

\section{Contribuição dos Autores}

Todos os autores foram responsáveis pela reflexão, análise e redação das ideias desenvolvidas no artigo.

\section{Notas}

${ }^{1}$ Estas reflexôes foram apresentadas no II Simpósio Internacional de Terapia Ocupacional Social, realizado em São Paulo, em 2011.

${ }^{2}$ Conforme já havia sido estabelecido na NOB-RH/SUAS, de 2005.

${ }^{3}$ Grupo interinstitucional de estudos, formação e açốes pela cidadania de crianças, adolescentes e adultos em processos de ruptura das redes sociais de suporte. 
${ }^{4}$ As atividades configuram uma, dentre outras frentes de trabalho do grupo, e ocorrem na forma de projeto de extensão universitária do Curso de Terapia Ocupacional da USP, também oferecendo formação prática para estudantes de terceiro e quarto anos.

${ }^{5}$ Convém lembrar-se dos problemas envolvendo a posição da mulher na sociedade contemporânea. Se, por um lado deve-se reconhecer sua crescente participaçáo no mercado de trabalho e na vida pública, por outro é fundamental dar atenção ao fato de que predomina sua incorporação em atividades subalternas e mal remuneradas, e que a sobrecarga de atividades e responsabilidades lhes dificulta a construção da autonomia, especialmente em condiçóes de pobreza. Para maior delineamento do tema, ver Brasil (2008). 